\title{
Hydroxyeicosatetraenoic Acid Metabolism in Cultured Human Skin Fibroblasts Evidence for Peroxisomal $\beta$-Oxidation
}

Joel A. Gordon, ${ }^{*}$ Paul H. Figard, ${ }^{\ddagger}$ and Arthur A. Spector**

Departments of ${ }^{*}$ Internal Medicine and ${ }^{\ddagger}$ Biochemistry, The University of Iowa College of Medicine, Iowa City, Iowa 52242

\begin{abstract}
To determine whether the peroxisome is responsible for hydroxyeicosatetraenoic acid (HETE) oxidation, 12- and 15HETE oxidation was measured in normal and peroxisomal deficient skin fibroblasts from patients with Zellweger's (cerebrohepatorenal) syndrome. When incubated for $1 \mathrm{~h}$ with normal fibroblasts, reverse phase HPLC indicated that $24 \%$ of the 12-HETE radioactivity was converted to one major polar metabolite. Chemical derivatization followed by reverse phase HPLC and TLC indicated that this metabolite is 8-hydroxyhexadecatrienoic acid [16:3(8-OH)]. Similarly, 33\% of the added 15-HETE was also converted to a more polar metabolite. Neither 12- nor 15-HETE were converted to any metabolites by the peroxisomal deficient (Zellweger) cells. No defect in HETE oxidation was found in other human fibroblast cell lines with diverse metabolic abnormalities. Zellweger fibroblasts accumulated increased amounts of 12-HETE, compared with normal fibroblasts. As in the normal cells, most of the 12-HETE incorporated into Zellweger fibroblasts was present in the choline and ethanolamine phosphoglycerides. Protein synthesis, lysosomal acid lipase activity, and mitochondrial butyrate oxidation were not impaired in the Zellweger fibroblasts. Since the Zellweger cells do not convert 12- and 15HETE to oxidative metabolites, peroxisomes appear to be the cellular organelle responsible for HETE oxidation. (J. Clin. Invest. 1990. 85:1173-1181.) HETES • peroxisomes $\bullet \beta$-oxidation
\end{abstract}

\section{Introduction}

Hydroxyeicosatetraenoic acids (HETEs) ${ }^{1}$ are 20-carbon atom derivatives of arachidonic acid produced almost exclusively via the action of stereospecific cytosolic lipoxygenase enzymes

Presented in part at the Annual Meeting of the American Federation of Clinical Research, Washington, DC, 29 April 1989 and published in abstract form (1989. Clin. Res. 37:374a).

Address reprint requests to Dr. Gordon, Department of Internal Medicine, E 300 G GH, University of Iowa College of Medicine, Iowa City, IA 52242.

Received for publication 13 June 1989 and in revised form 14 November 1989.

1. Abbreviations used in this paper: HETE, hydroxyeicosatetraenoic acid; MDCK, Madin Darby canine kidney; MUO, 4-methylumbelliferyl oleate; DPBS, Dulbecco's phosphate-buffered saline; 16:3 (8-OH), 8-hydroxyhexadecatrienoic acid; 16:3 (11-OH), 11-hydroxyhexadecatrienoic acid.

\footnotetext{
J. Clin. Invest.

(c) The American Society for Clinical Investigation, Inc.

0021-9738/90/04/1173/09 \$2.00

Volume 85, April 1990, 1173-1181
}

that insert a single oxygen molecule into arachidonic acid at carbons 5,12 , or 15 (1). The initial product, an unstable hydroperoxide, is either spontaneously or peroxidatively reduced to the corresponding monohydroxylated product, a HETE, which is the stable end product. Two major forms of HETEs are 12-HETE, synthesized largely by activated macrophages and platelets $(2,3)$ and 15 -HETE, synthesized by activated neutrophils, eosinophils, macrophages, and reticulocytes (1). 12- and 15-HETE are potent chemotactic and chemokinetic factors (4), are mitogenic for bovine aortic endothelial cells (5), inhibit prostaglandin formation in cultured endothelial and renal epithelial cells $(6,7)$, modulate lipoxygenase activity in human leukocytes $(8,9)$, inhibit human vascular cycloxygenase activity (10), and stimulate tracheal mucus secretion (11).

12- and 15-HETE are taken up by cells and incorporated primarily into phospholipids. 12-HETE is preferentially incorporated into the choline and the ethanolamine phosphoglycerides (7), whereas a substantial fraction of 15-HETE is recovered in the inositol phosphoglycerides $(12,13)$. In addition, $12-$ and 15-HETE are converted to metabolites that are released to the extracellular medium. Renal epithelial cells, vascular smooth muscle cells, and murine cerebral microvascular endothelium recently have been shown to convert 12-HETE to a 16-carbon metabolite identified as 8-hydroxyhexadecatrienoic acid [16:3(8-OH)] (14-16). Likewise, endothelial cells convert 15-HETE to 11-hydroxyhexadecatrienoic acid [16:3(11-OH)] (12). These 16-carbon metabolites are most likely produced through oxidative removal of 4 carbons from the carboxyl terminus of the HETE.

Zellweger's syndrome, also known as the cerebrohepatorenal syndrome, is an autosomal recessive disorder characterized functionally by the accumulation of phytanic acid and very long chain fatty acids, diminished plasmalogen, and bile acid biosynthesis. Clinically, the syndrome is associated with failure to thrive, hepatomegaly, renal cortical cysts, severe hypotonia, epileptic seizures, psychomotor retardation, and premature death in the first 6-12 mo of life (17). The anatomic abnormality present in this syndrome was unknown until 1973 when Goldfischer first reported that liver and kidney tissue from infants with the Zellweger syndrome had no demonstrable peroxisomes (18). Peroxisomes catalyze the chain-shortening of long- and very-long chain fatty acids (19), as well as the carboxyl side chains of prostaglandin $E_{2}$ and prostaglandin $F_{2 \alpha}$ $(20,21)$. This information, combined with our recent observation that 4-pentenoic acid, an inhibitor of mitochondrial $\beta$ oxidation, failed to reduce the conversion of 12-HETE to 16:3(8-OH) in cultured renal epithelial cells (14) led us to suggest that HETE oxidation may occur in peroxisomes. We now report that skin fibroblasts obtained from patients with Zellweger's syndrome do not convert 12- or 15-HETE to chainshortened metabolites, thus supporting the hypothesis that HETE oxidation is a peroxisomal process. 


\section{Methods}

Cell culture. Skin fibroblasts from patients with Zellweger's syndrome were stored in liquid nitrogen with $7 \%$ dimethyl sulfoxide and $20 \%$ fetal bovine serum and studied between passages 1-7. The diagnosis of Zellweger's syndrome had been previously confirmed by Dr. Hugo Moser of the Kennedy Institute of the Johns Hopkins University in Baltimore, MD, who measured elevated levels of very long chain fatty acids in both the plasma and cultured skin fibroblasts from each of the three patients that we studied (17). The cells were grown to confluency in Eagle's minimal essential medium (MEM) with Earle's salts and 10 or $20 \%$ heat inactivated fetal bovine serum (Hy-Clone, Logan, UT) supplemented with glutamine, essential vitamins, nonessential amino acids (Gibco Laboratories, Grand Island, NY), $50 \mu \mathrm{g} / \mathrm{ml}$ gentamicin, and buffered to $\mathrm{pH} 7.4$ with $15 \mathrm{mM}$ Hepes and $\mathrm{NaHCO}_{3}$. After growth in tissue culture flasks with either 25 or $75 \mathrm{~cm}^{2}$ surface area (Corning Glass Works, Corning, NY), the fibroblasts were passed into 6-well tissue culture plates with a surface area of $10 \mathrm{~cm}^{2} /$ well (Tissue Culture Cluster 6; Costar, Cambridge, MA). Experiments were performed when the $10-\mathrm{cm}^{2}$ cultures were $80-100 \%$ confluent. Cultures were maintained in a temperature- and humidity-controlled incubator $\left(\mathrm{CO}_{2}\right.$ incubator model 3028 ; Forma Scientific, Marietta, $\mathrm{OH}$ ) at $37^{\circ} \mathrm{C}$ with 95\% air-5\% $\mathrm{CO}_{2}$ as the gas phase. Skin fibroblasts without known abnormalities in peroxisomal function and from patients with cholestryl ester storage disease and pseudo-Hurler's polylipodystrophy type III were prepared and maintained in an identical fashion. Maden Darby canine kidney (MDCK) cells were grown and maintained as previously described (14). The DNA content of the cultures was measured fluorometrically (22).

Incubation and lipid analysis. After removal of the maintenance medium, the cultures were washed twice with Dulbecco's PBS (DPBS) containing $0.1 \mu \mathrm{M}$ bovine serum albumin (BSA). After addition of 1 $\mathrm{ml}$ of Eagle's MEM with $0.1 \mu \mathrm{M}$ BSA containing $1 \mu \mathrm{M}$ 12-HETE (12-S-HETE, $0.1 \mathrm{mg} / \mathrm{ml}$; Cayman Chemical Corp., Ann Arbor, MI) and $0.2 \mu \mathrm{Ci} / \mathrm{ml} 12(S)$ hydroxy-[5,6,8,9,11,12,14,15,(n)- $\left.{ }^{3} \mathrm{H}\right]$ eicosatetraenoic acid $(119 \mathrm{Ci} / \mathrm{mmol}$; Amersham Corp., Arlington Heights, IL), or $1 \mathrm{ml}$ of $1 \mu \mathrm{M}$ 15-HETE(15-S-HETE, Cayman Chemical) and $0.2 \mu \mathrm{Ci} /$ $\mathrm{ml}$ 15(S)-[5,6,8,9,11,12,14,15- $\left.{ }^{3} \mathrm{H}\right]-15$-HETE $(213 \mathrm{Ci} / \mathrm{mmol}$; Amersham Corp.), the cultures were incubated at $37^{\circ} \mathrm{C}$ for periods of time up to $2 \mathrm{~h}$. At the appropriate time, the medium was removed and the radioactive lipids assayed by HPLC.

To compare the uptake of 12-HETE and arachidonic acid, either 1 $\mathrm{ml}$ of $1 \mu \mathrm{M}\left[{ }^{3} \mathrm{H}\right]-12$-HETE, or $1 \mathrm{ml}$ of $1 \mu \mathrm{M}$ arachidonic acid (NuCheck Prep, Elysian, MN) and $0.2 \mu \mathrm{Ci} / \mathrm{ml}\left[5,6,8,9,11,12,14,15-{ }^{3} \mathrm{H}\right]$ arachidonic acid $(222 \mathrm{Ci} / \mathrm{mmol}$, Amersham Corp.), were incubated with confluent cultures of normal or Zellweger human skin fibroblasts for 30-240 min. At the appropriate time, the medium was removed, the cells washed, and the cell lipids extracted and assayed for radioactivity (7). The distribution of the incorporated radioactivity between neutral lipids and phospholipids was assayed by TLC (7).

For saponification of the cellular lipid extract, $1 \mathrm{ml}$ of $95 \%$ ethanol was added to dissolve the lipid residue, then $50 \mu \mathrm{l}$ of $33 \% \mathrm{KOH}$ in $\mathrm{H}_{2} \mathrm{O}$ was added and the mixture vortexed vigorously. The solution was heated to $70^{\circ} \mathrm{C}$ for $45 \mathrm{~min}$, cooled, $1 \mathrm{ml}$ of $\mathrm{H}_{2} \mathrm{O}$ was added and the tube was vortexed vigorously again. After neutralization with $12 \mathrm{~N} \mathrm{HCl}$ and extraction with three $1-\mathrm{ml}$ volumes of $n$-heptane, the upper phases were collected and pooled. The extract was dried under $\mathrm{N}_{2}$, resuspended in $50 \mu \mathrm{l}$ acetonitrile, and the radioactive products separated by reverse-phase HPLC.

To determine if the mitochondrial $\beta$-oxidation inhibitor 4-pentenoic acid (Sigma Chemical Co., St. Louis, MO) could prevent the formation of the oxidative metabolites from 12- and 15-HETE, normal fibroblasts were incubated for $1 \mathrm{~h}$ in $1 \mathrm{ml}$ of Eagle's modified MEM with $0.1 \mu \mathrm{M}$ BSA supplemented with $0.1 \mathrm{mM}$ 4-pentenoic acid. Then, $1 \mathrm{ml}$ of Eagle's modified MEM with $0.1 \mu \mathrm{M}$ BSA containing $1 \mu \mathrm{M}$ $\left[{ }^{3} \mathrm{H}\right]-12$ - or $\left[{ }^{3} \mathrm{H}\right]-15-\mathrm{HETE}$ was added to the cultures for an additional $1 \mathrm{~h}$. At the end of the incubation, the medium was removed and the radioactive lipids assayed by HPLC.
For comparison of 12-HETE metabolism between renal tubular epithelial (MDCK) cells and normal human skin fibroblasts, we incubated $8 \mathrm{ml}$ of Eagle's MEM with $0.1 \mu \mathrm{M}$ BSA containing $0.5 \mu \mathrm{M}$ $\left[{ }^{3} \mathrm{H}\right]-12$-HETE $(0.2 \mu \mathrm{Ci} / \mathrm{ml})$ in one confluent $75-\mathrm{cm}^{2}$ surface area flask (Corning Glass Works) containing either MDCK cells or normal fibroblasts. After $2 \mathrm{~h}$, the medium was removed and prepared for HPLC analysis.

Fatty acid oxidation. To determine the effect of 4-pentenoic acid on myristic acid $\beta$-oxidation, normal human skin fibroblasts were grown to confluency in culture flasks with $25 \mathrm{~cm}^{2}$-surface area. The cells were incubated in $4.0 \mathrm{ml}$ of modified MEM supplemented with $0.1 \mathrm{mM}$ 4-pentenoic acid for $1 \mathrm{~h}$. As controls, flasks without 4-pentenoic acid and flasks without cells also were incubated. After $1 \mathrm{~h}$, the caps were removed and $1.0 \mathrm{ml}$ of modified MEM with or without $0.1 \mathrm{mM}$ 4-pentenoic acid supplemented with $5 \mu \mathrm{M}$ BSA and $15 \mu \mathrm{M}\left[1-{ }^{14} \mathrm{C}\right]-$ myristic acid $(54 \mathrm{mCi} / \mathrm{mmol}$; Research Products International, Mount Prospect, IL) was added to the appropriate flasks for an additional $1 \mathrm{~h}$. The flasks were then sealed with special rubber tops with attached plastic chambers containing $250 \mu$ l of hyamine hydroxide to trap the released $\left[1-{ }^{14} \mathrm{C}\right] \mathrm{CO}_{2}$. After $1 \mathrm{~h}, 100 \mu \mathrm{l}$ of acidified DPBS was slowly injected through the rubber tops into the cultures. After $45 \mathrm{~min}$, the rubber tops were removed, the outside of the chambers washed with 95\% ethanol, dried, cut away, placed in scintillation vials and counted in $15 \mathrm{ml}$ of Neutralizer scintillation cocktail (Research Products International).

Fatty acid competition for $\beta$-oxidation. To determine if other fatty acids could compete with the HETEs for oxidation, we incubated normal fibroblasts in $0.5 \mathrm{ml}$ Eagle's modified MEM with $0.1 \mu \mathrm{M}$ BSA supplemented with 1 or $5 \mu \mathrm{M}$ nonradiolabeled 5-HETE, 15-HETE, ricinoleic acid, butyric acid, eicosapentenoic acid, docosahexenoic acid, or phytanic acid. Simultaneously, $0.5 \mathrm{ml}$ of Eagle's MEM containing $0.1 \mu \mathrm{M}$ BSA supplemented with $2 \mu \mathrm{M}\left[{ }^{3} \mathrm{H}\right]-12$-HETE was added. As a control, several cultures were incubated with $1 \mu \mathrm{M}$ $\left[{ }^{3} \mathrm{H}\right]-12$-HETE without any competing fatty acid. After $1 \mathrm{~h}$, the medium was removed and assayed for radioactivity by reverse-phase HPLC.

HPLC. After addition of $4 \mathrm{ml}$ of Budget Solve scintillation solution (Research Products International Corp.) to a $25-\mu$ l aliquot of the medium, the radioactivity was measured in a liquid scintillation spectrometer (LS7000; Beckman Instruments, Inc., Fullerton, CA). Quenching was monitored with the ${ }^{226} \mathrm{Ra}$ external standard. Additional aliquots of the medium containing 10,000-15,000 cpm were transferred to a siliconized glass vial, acidified with $10 \mu \mathrm{l}$ of $2.4 \mathrm{~N} \mathrm{HCl}$, and added to $40 \mu \mathrm{l}$ acetonitrile. Reverse-phase HPLC was performed on a Beckman 332 Chromatograph containing a $4.6 \times 250 \mathrm{~mm}$ Vydac column with $\mathrm{C}_{18}$ reverse-phase $5 \mu \mathrm{m}$ spherical packing. The solvent mixture consisted of water adjusted to $\mathrm{pH} 3.4$ with phosphoric acid and an increasing acetonitrile gradient from 29 to $100 \%$ over $55 \mathrm{~min}$ (7). Radioactivity was detected by passing the column effluent mixed with Budget Solve scintillation solution through a HPLC radioactivity flow detector (Radiomatic Flo-One Beta; Canberra Corp., Tampa, FL)

Medium from the incubations with normal fibroblasts and MDCK cells was transferred to a large, siliconized glass tube and acidified to pH 3.5 with $12 \mathrm{~N} \mathrm{HCl} .2 \mathrm{ml}$ of ethyl acetate was added, and the tube was vortexed vigorously and centrifuged for $10 \mathrm{~min}$ at $400 \mathrm{~g}$ to separate the phases. After the ethyl acetate was removed, the extraction was repeated twice and the ethyl acetate extracts were pooled. The ethyl acetate was then evaporated under a stream of nitrogen and the lipids were resuspended in $1 \mathrm{ml}$ of methanol.

Analytical HPLC was first carried out on a 3- $\mu$ laliquot from each extract to identify the retention time and determine the radioactivity contained in each metabolite. The aliquot was first dried under a stream of nitrogen and resuspended in $30 \%$ acetonitrile $/ 70 \%$ acidified $\mathrm{H}_{2} \mathrm{O}$ before injection. The solvent mixture consisted of acidified water and an increasing acetonitrile gradient from 30 to $100 \%$ over $45 \mathrm{~min}$. Fractions were then collected from the remainder of the sample at 1 -min intervals to isolate the major metabolite. This fraction, which 
eluted in both the normal fibroblasts and the MDCK cells incubations at $17.6 \mathrm{~min}$, was mixed with an equal volume of water and then isolated by extraction with 3 vol of ethyl acetate.

Preparation of derivatives. The major metabolites in methanol solution were methylated with diazomethane in ether (23). The methyl ester was converted to the trimethylsilyl ether by incubation with bis (trimethylsilyl) trifluoroacetamide and $1 \%$ trimethylchlorosilane (Sylone BFT; Supelco, Inc., Bellefonte, PA) in pyridine (24). The methyl ester derivatives dissolved in pyridine were acetylated by reaction with acetic anhydride for $16 \mathrm{~h}$.

Identification of derivatives. An aliquot of underivatized metabolite as well as each of the three derivatives prepared from both the normal fibroblast and MDCK cell metabolites were dried under a stream of nitrogen, resuspended in $30 \%$ acetonitrile $/ 70 \%$ acidified water, and injected into the reverse-phase HPLC column using the acetonitrile gradient solvent mixture described above. Radioactivity was measured with the Radiomatic HPLC radioactivity flow detector.

An additional aliquot of the underivatized metabolites, the methyl esters and the acetylated derivatives were spotted on silica gel TLC plates (Linear K; Whatman Chemical Separation, Clifton, NJ). Separation of the underivatized metabolite from its methyl ester and acetylated derivative was accomplished using an ethyl acetate/acetic acid, 100:0.3 (vol/vol) solvent system. The radioactivity present in the metabolite and its methyl ester and acetylated derivative was measured with a TLC plate scanner (model RS; Radiomatic Instruments and Chemical Co.). This system used an automated, computer controlled detector with a position-sensitive proportional flow counter and a multichannel analyzer.

Protein synthesis. After removal of the maintenance medium, Zellweger and normal human skin fibroblasts were washed twice with DPBS at $37^{\circ} \mathrm{C}$ and then incubated for $4 \mathrm{~h}$ in $1 \mathrm{ml}$ of Eagle's MEM, leucine-free supplemented with $0.4 \mu \mathrm{Ci} / \mathrm{ml}$ of $\left.\mathrm{L}-{ }^{3} \mathrm{H}\right]$ leucine $(190 \mathrm{Ci} /$ mmol; Amersham Corp.). An identical set of both normal and Zellweger cultures were supplemented at the same time with $2.5 \mu \mathrm{M} 12$ HETE. After $4 \mathrm{~h}$, the incubation medium was removed and $1 \mathrm{ml}$ of $5 \%$ TCA was added for $1 \mathrm{~h}$ at $4^{\circ} \mathrm{C}$. After removing the supernatant solution, the cells were gently washed with buffer, and $750 \mu \mathrm{l}$ of $0.25 \mathrm{~N}$ $\mathrm{NaOH}$ was added at $37^{\circ} \mathrm{C}$ for $30 \mathrm{~min}$. A $500-\mu$ l aliquot of the solution then was placed in a scintillation vial. After neutralizing with $50 \mu$ lof 6 $\mathrm{N} \mathrm{HCl}, 4.5 \mathrm{ml}$ of Budget-Solve Scintillation Solution was added and radioactivity measured in a liquid scintillation spectrometer. The total DNA content in the cultures also was determined (22).

$\left[{ }^{3} \mathrm{H}\right]$ Thymidine incorporation. After removal of the maintenance medium, Zellweger and normal human skin fibroblasts were washed twice with DPBS at $37^{\circ} \mathrm{C}$ and then incubated for $4 \mathrm{~h}$ in $1 \mathrm{ml}$ of Eagle's modified MEM with 5\% fetal bovine serum supplemented with $1 \mu \mathrm{Ci}$ / $\mathrm{ml}$ of $\left[{ }^{3} \mathrm{H}\right]$ thymidine $(91 \mathrm{Ci} / \mathrm{mmol}$, Amersham Corp.). At the same time, an identical set of both normal and Zellweger cultures were supplemented with $2.5 \mu \mathrm{M}$ 12-HETE. After $4 \mathrm{~h}$, the incubation medium was removed, the cells were harvested, and the radioactivity determined as described above.

Butyrate oxidation. Cultures of normal and Zellweger fibroblasts were subcultured into 24-well tissue culture plates by seeding 30-50 $\mu \mathrm{g}$ of cell protein/well, and the cells were grown to confluency over the next $24 \mathrm{~h}$. The medium was removed, Eagle's MEM containing $\left[{ }^{14} \mathrm{C}\right]-$ butyrate $(1.0 \mu \mathrm{Ci} / \mathrm{ml})$ was added, and the cultures incubated for $24 \mathrm{~h}$ (25). The medium was removed, the cells washed, and the monolayer sonicated into $150 \mu \mathrm{l}$ of cold $10 \%$ TCA. After centrifugation, the pellet was resuspended in $500 \mu \mathrm{l}$ of deionized $\mathrm{H}_{2} \mathrm{O}, 400 \mu \mathrm{l}$ was aspirated into a scintillation vial and $4.0 \mathrm{ml}$ of Budget-Solve scintillation solution was added. After waiting overnight, the radioactivity was determined in a liquid scintillation spectrometer. The remaining $400-\mu l$ aliquot was used to determine the cell protein content (26).

Acid lipase activity. 4-Methylumbelliferyl oleate (MUO) hydrolase activity was measured in cultures of normal and Zellweger human skin fibroblasts according to the method of Sando and Rosenbaum (27). The assay mixture contained a final volume of $0.4 \mathrm{ml}$ and consisted of $50 \mu \mathrm{M}$ MUO, $80 \mu \mathrm{M}$ phosphatidylcholine, $300 \mu \mathrm{M}$ sodium tauro- deoxycholate, and $0.05 \mathrm{M}$ sodium acetate, $\mathrm{pH}$ 4.1. The reaction was initiated by addition of sample to buffer that had been incubated for several minutes at $31^{\circ} \mathrm{C}$ with the sonicated lipids. The rate of 4-methylumbelliferone release was monitored with a computer aided fluorometer.

Statistics. Comparisons between groups were made with an analysis of variance, and significance between groups $(P<0.05)$ was tested according to the method of Scheffé (28).

\section{Results}

12-HETE oxidation. During a 1-h incubation, normal human skin fibroblasts converted $24 \%$ of the $\left[{ }^{3} \mathrm{H}\right]-12$-HETE to a single radioactive metabolite with a retention time on reverse-phase HPLC of 29.2 min (Fig. 1, top). Formation of this compound

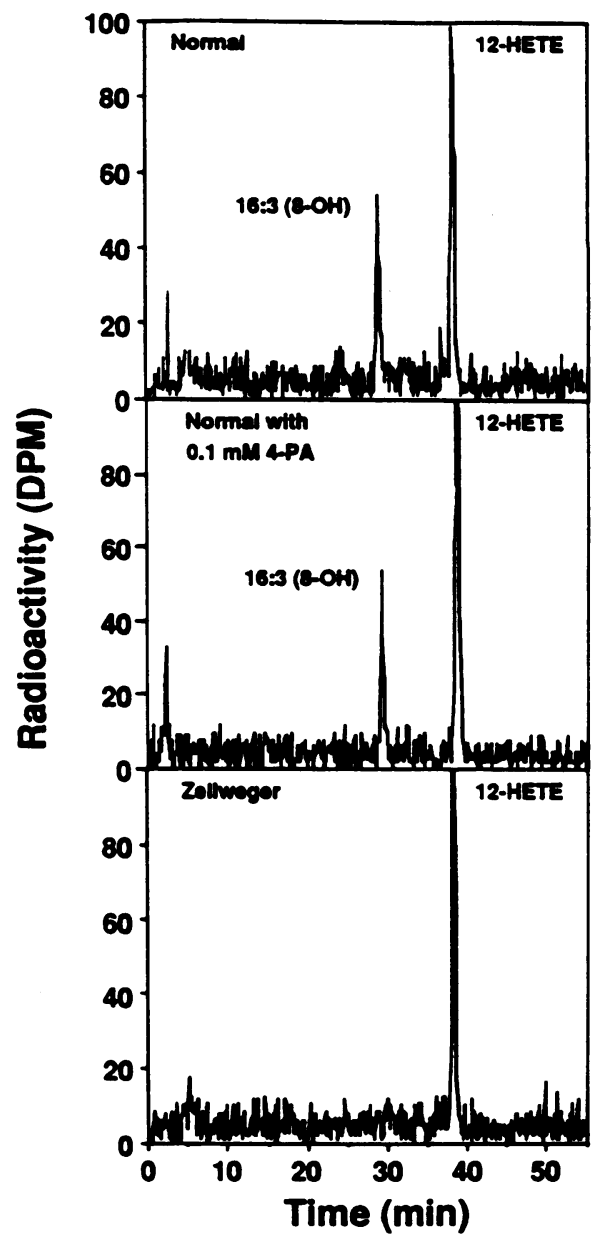

Figure 1. HPLC profile of 12-HETE radioactivity released into the medium by normal and Zellweger human skin fibroblasts. Normal fibroblasts (top) were incubated with $1 \mu \mathrm{M}\left[{ }^{3} \mathrm{H}\right]-12$-HETE in serumfree MEM containing $0.1 \mu \mathrm{M}$ BSA for $1 \mathrm{~h}$. A separate culture of normal fibroblasts was incubated initially for $1 \mathrm{~h}$ with $0.1 \mathrm{mM}$ 4-pentenoic acid (PA), and $1 \mu \mathrm{M}\left[{ }^{3} \mathrm{H}\right]-12$-HETE was added subsequently for an additional $1 \mathrm{~h}$ (middle). Zellweger fibroblasts (bottom) were incubated with $1 \mu \mathrm{M}\left[{ }^{3} \mathrm{H}\right]-12$-HETE in serum-free MEM containing 0.1 $\mu \mathrm{M}$ BSA for $2 \mathrm{~h}$. After the medium was removed, an aliquot containing at least $10,000 \mathrm{dpm}$ was acidified with $10 \mu \mathrm{l}$ of $1 \mathrm{~N} \mathrm{HCl}$, mixed with $40 \mu$ l of HPLC grade acetonitrile, and injected into the reverse-phase HPLC. Radioactivity was assayed with an on-line, flow through scintillation counter. 12-HETE has a retention time of 38.2 min and the major metabolite of 12-HETE [(16:3(8-OH)], produced in the normal human fibroblasts (top and middle), elutes at $29.2 \mathrm{~min}$. 
was not reduced by prior incubation of the fibroblasts with 4-pentenoic acid, an inhibitor of mitochondrial $\beta$-oxidation (Fig. 1, middle). In contrast, when skin fibroblasts from patients with Zellweger's syndrome were incubated with $\left[{ }^{3} \mathrm{H}\right]-12-H E T E$ for $2 \mathrm{~h}$ and the medium analyzed in an identical fashion, there was no conversion to any metabolic products (Fig. 1, bottom).

To determine the time course of formation of this metabolite in normal fibroblasts and whether Zellweger fibroblasts might produce this metabolite only at time points $2 \mathrm{~h}$, we compared the products formed by normal and Zellweger human skin fibroblasts incubated for up to $2 \mathrm{~h}$ with $1.0 \mu \mathrm{M}$

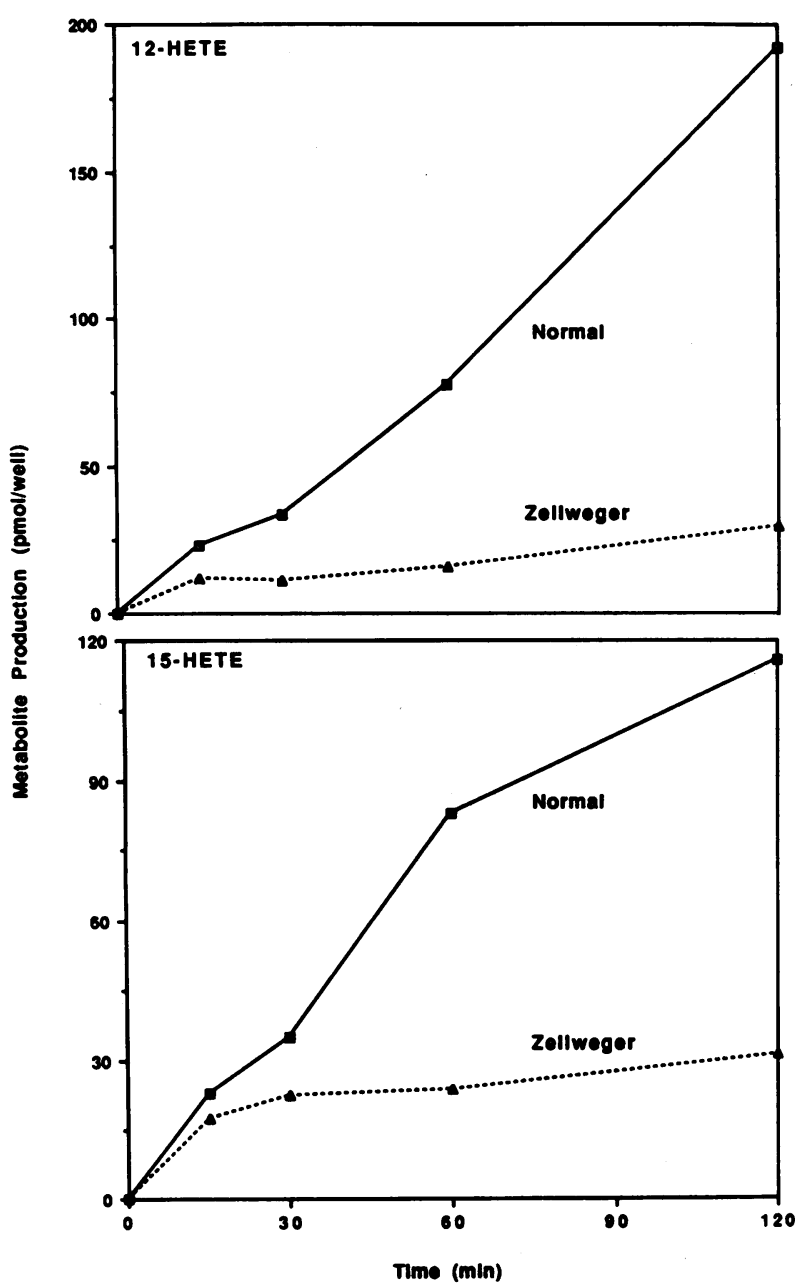

Figure 2. Comparison of the time-dependent production of the major metabolite of 12- and 15-HETE in normal and Zellwager human skin fibroblasts. Normal (solid line) and Zellweger (dashed line) human skin fibroblasts were tested as described in Fig. 1, except that the incubations were $15,30,60$, or $120 \mathrm{~min}$. The medium subsequently was removed, the lipids extracted with ethyl acetate, and an aliquot containing at least $10,000 \mathrm{dpm}$ was injected into the reverse-phase HPLC. Using a gradient of 30-100\% acetonitrile over 45 min, the major 12-HETE metabolite elutes at $17.6 \mathrm{~min}$ and the major 15-HETE metabolite elutes at $16.6 \mathrm{~min}$. From the specific activity of the incubation media and the percent of radioactivity corresponding to the 12- and 15-HETE major metabolites obtained from the HPLC analysis, the total amount (picomoles) of 12- and 15HETE radioactivity released into the medium as the metabolite was calculated. Each value represents a single measurement. $\left[{ }^{3} \mathrm{H}\right]-12-\mathrm{HETE}$. As shown in Fig. 2 (top), normal human fibroblasts (solid line) converted 12-HETE to its major metabolite in a time dependent fashion. In contrast, Zellweger fibroblasts (dashed line) converted relatively little 12-HETE to this metabolite.

The major metabolite of 12-HETE produced by MDCK cells has been previously identified by gas chromatographymass spectrometry as $16: 3(8-\mathrm{OH})(14)$. To determine whether normal fibroblasts produced the same metabolite, we incubated normal fibroblasts and MDCK cells with $\left[{ }^{3} \mathrm{H}\right]-12-\mathrm{HETE}$ for $2 \mathrm{~h}$. The major metabolite from each cell line was isolated and derivatized to form the methyl ester, the trimethylsilyl ether, or the acetylated compound. Table I contains the results of reverse-phase HPLC and TLC analysis of these various derivatives. HPLC retention times of the underivatized metabolite, the methyl ester, the trimethylsilyl ether, and the acetylated derivatives from both MDCK cells and normal fibroblasts were identical. Furthermore, the TLC $R_{\mathrm{f}}$ values of the underivatized compound, the methyl ester, and the acetylated derivatives were also identical. Based on identical chromatographic properties of the underivatized and derivatized metabolites from MDCK cells and normal skin fibroblasts, we conclude that the major metabolite from normal skin fibroblasts, as in the case of MDCK cells, is $16: 3(8-\mathrm{OH})$.

15-HETE oxidation. To determine the specificity of defective oxidation in the Zellweger cells, $\left[{ }^{3} \mathrm{H}\right]-15-\mathrm{HETE}$ was tested under identical conditions. Previous work has indicated that 15-HETE can be oxidized to a similar 16 carbon polar metabolite, 16:3(11-OH) (12). When incubated with normal human skin fibroblasts, $\left[{ }^{3} \mathrm{H}\right]-15-\mathrm{HETE}$ was converted to several more polar metabolites, including a major one which migrated at $31.2 \mathrm{~min}$ and comprised $34 \%$ of the total radioactivity detected (Fig. 3, top). Prior incubation of the fibroblasts with 4-pentenoic acid did not reduce formation of these metabolites (Fig. 3, middle). Finally, as in the case of 12-HETE, 15-HETE was not converted to any metabolites by the fibroblasts from patients with Zellweger's syndrome (Fig. 3, bottom). In summary, HPLC properties of the major 15-HETE metabolite produced by the normal fibroblasts are similar to properties reported for

Table I. HPLC and TLC Properties of the 12-HETE Metabolite Produced by MDCK Cells and Normal Human Fibroblasts

\begin{tabular}{lccccc}
\hline & \multicolumn{2}{c}{$\begin{array}{c}\text { HPLC Retention time } \\
\text { (min) }\end{array}$} & & \multicolumn{2}{c}{ TLC $R_{\boldsymbol{r}}$} \\
\cline { 2 - 3 } \cline { 5 - 6 } \multicolumn{1}{c}{ Metabolite } & MDCK & Fibroblast & & & \\
& & & & & \\
\hline Unmodified & 17.6 & 17.6 & & 0.306 & Fibroblast \\
Methyl ester & 24.5 & 24.5 & & 0.637 & 0.306 \\
Trimethylsilyl ether & 24.5 & 24.4 & & ND & ND \\
Acetylated & 37.9 & 37.9 & & 0.663 & 0.669 \\
& & & & &
\end{tabular}

Confluent cultures of MDCK cells and normal human fibroblasts were incubated with $0.05 \mu \mathrm{M}\left[{ }^{3} \mathrm{H}\right]-12$-HETE for $2 \mathrm{~h}$. The medium was removed, lipids extracted with ethyl acetate, and the major, polar metabolite was isolated by reverse-phase HPLC. A gradient from 30 to $100 \%$ acetonitrile was used, and radioactivity was detected with an on-line radioactive flow detector. For TLC, Whatman silica gel laned plates were exposed to a solvent mixture of ethyl acetate/acetic aid, 100/0.3 (vol/vol), and the radioactivity was detected with a radioactive plate scanner. 


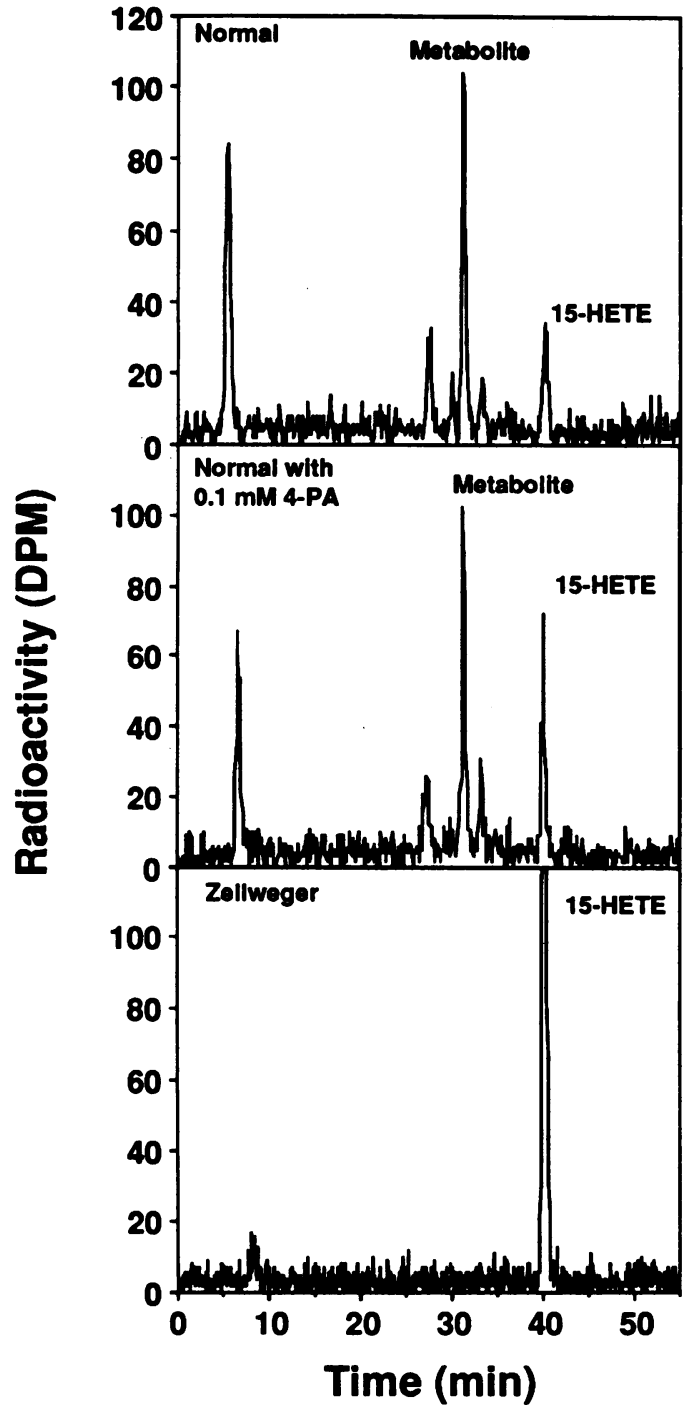

Figure 3. HPLC profile of 15-HETE radioactivity released into the medium by normal and Zellweger human skin fibroblasts. The conditions were the same as described in Fig. 1, except that the fibroblasts were incubated with $1.0 \mu \mathrm{M}\left[{ }^{3} \mathrm{H}\right]-15$-HETE in serum-free MEM containing $0.1 \mu \mathrm{M}$ BSA. (Top) Normal fibroblasts; middle, normal fibroblasts plus 0.1 mM 4-pentenoic acid (PA); bottom, Zellweger fibroblasts. 15-HETE has a retention time of $40.1 \mathrm{~min}$ and the major metabolite of 15-HETE, produced in the normal human fibroblasts (top and middle), elutes at $31.2 \mathrm{~min}$.

$16: 3(11-\mathrm{OH})(12)$; further identification of this product was not undertaken.

Additional studies were done to determine the time course of formation of the major metabolite of 15-HETE in normal fibroblasts and whether Zellweger fibroblasts produced this metabolite at time points $2 \mathrm{~h}$. As shown in Fig. 2 (bottom), normal human skin fibroblasts (solid line) converted increasing amounts of 15-HETE to the major metabolite whereas Zellweger fibroblasts (dashed line) produced much less of this metabolite throughout the $2-\mathrm{h}$ incubation.

Fatty acid oxidation. To demonstrate the effect of 4-pentenoic acid on fatty acid $\beta$-oxidation, we incubated $\left[1-{ }^{14} \mathrm{C}\right] \mathrm{my}-$ ristic acid with normal human fibroblasts and measured the effect of this inhibition on the production of ${ }^{14} \mathrm{CO}_{2}$. Control cultures produced $32.2 \pm 5$ pmol $\mathrm{CO}_{2}$ compared to $17.8 \pm 5.8$ pmol $\mathrm{CO}_{2}$ released by cultures incubated with a $0.1-\mathrm{mM} 4-$ pentenoic acid $(P<0.02$, two-way analysis of variance). Therefore, incubation with $0.1 \mathrm{mM}$ 4-pentenoic acid reduces the $\beta$-oxidation of myristic acid by $45 \%$.

HETE uptake. To determine whether the failure of Zellweger's fibroblasts to form $16: 3(8-\mathrm{OH})$ might be due to an inability of the cells to incorporate 12-HETE, 12-HETE uptake was measured. Uptake of both $\left[{ }^{3} \mathrm{H}\right]-12-\mathrm{HETE}$ and $\left[{ }^{3} \mathrm{H}\right]-$ arachidonic acid by normal and Zellweger fibroblasts was compared under identical conditions. As seen in Fig. 4, the uptake of arachidonic acid was virtually identical in both types of fibroblasts, whereas the uptake of 12-HETE in the Zellweger fibroblasts exceeded the uptake in normal fibroblasts at all of the time points tested. Therefore, the failure of the Zellweger cells to convert 12 -HETE to $16: 3(8-\mathrm{OH})$ is not due to an inability of these cells to take up 12-HETE.

Analysis of the cell lipid extracts revealed that the majority of the 12-HETE radioactivity taken up by both the normal and Zellweger fibroblasts was incorporated into phospholipids, primarily into choline phosphoglycerides, with lesser amounts in ethanolamine phosphoglycerides (Table II). No appreciable radioactivity was found in either the serine or inositol phosphoglycerides. Over time, more 12-HETE radioactivity remained in the choline and ethanolamine phosphoglyceride fractions in the Zellweger fibroblasts, whereas the normal fibroblasts accumulated 12-HETE radioactivity in triacylglycerol.

Analysis of cell lipid radioactivity. To rule out possible intracellular entrapment of 12- or 15-HETE metabolites, the identity of the radioactivity incorporated by the Zellweger fibroblasts was determined. After alkaline hydrolysis, reversephase HPLC demonstrated that only native, unmetabolized 12- or 15-HETE was contained in cell lipids (Fig. 5); no metabolites were detected in saponified cell extracts.

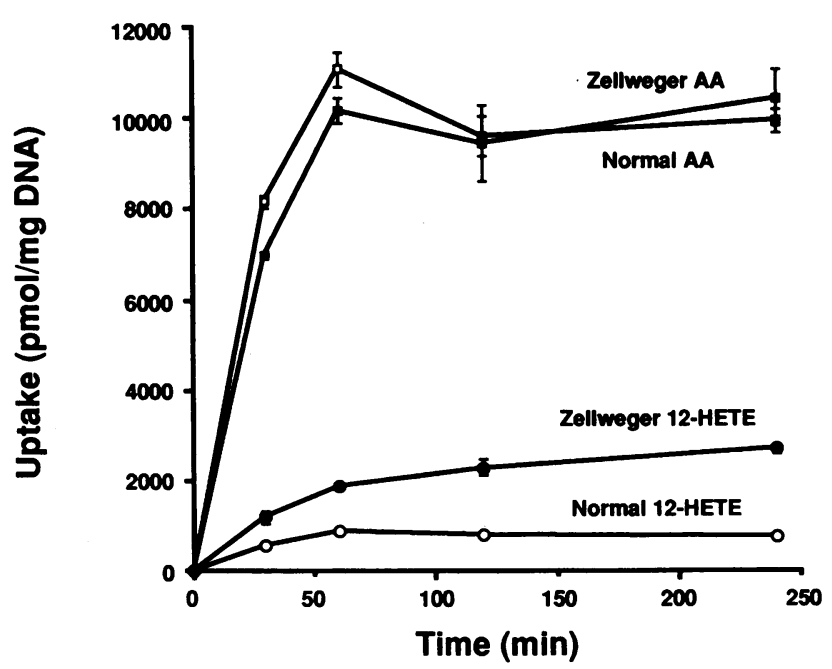

Figure 4. Comparison of arachidonic acid (AA) and 12-HETE uptake. Normal human and Zellweger skin fibroblasts were incubated for up to $240 \mathrm{~min}$ in $1 \mu \mathrm{M}\left[{ }^{3} \mathrm{H}\right]$ arachidonic acid or $1 \mu \mathrm{M}\left[{ }^{3} \mathrm{H}\right]-12-$ HETE in a serum-free MEM containing $0.1 \mu \mathrm{M}$ BSA. At the appropriate times, medium was removed, cells were washed with ice-cold buffer solution, and total cellular lipids were extracted with a chloroform/methanol mixture. Each point represents mean and SEM of three separate determinations. 
Table II. Distribution of 12-HETE Radioactivity Cell Lipids of Normal Human and Zellweger Skin Fibroblasts

\begin{tabular}{|c|c|c|c|c|c|c|c|c|}
\hline \multirow[b]{3}{*}{ Time } & \multicolumn{8}{|c|}{ Distribution of incorporated radioactivity in lipid fractions } \\
\hline & \multicolumn{2}{|c|}{ PC } & \multicolumn{2}{|c|}{ PE } & \multicolumn{2}{|c|}{ TAG } & \multicolumn{2}{|c|}{ HETE } \\
\hline & $\mathbf{N}$ & Z & $\mathbf{N}$ & z & $\mathrm{N}$ & $z$ & $\mathbf{N}$ & $\mathbf{z}$ \\
\hline \multicolumn{9}{|l|}{$\min$} \\
\hline 30 & $206(36)$ & $606(50)$ & $71(13)$ & $161(14)$ & $87(15)$ & $177(15)$ & $58(10)$ & $241(21)$ \\
\hline 60 & $305(38)$ & $956(52)$ & $91(11)$ & $232(13)$ & $170(21)$ & $330(18)$ & $160(20)$ & $333(18)$ \\
\hline 120 & $285(35)$ & $1219(56)$ & $82(10)$ & $287(13)$ & $273(33)$ & $374(17)$ & $127(16)$ & $287(13)$ \\
\hline 240 & $339(43)$ & $1493(56)$ & $77(10)$ & $372(14)$ & $219(28)$ & 454 (17) & $113(14)$ & $344(13)$ \\
\hline
\end{tabular}

Each value represents average distribution in two separate cultures from a single patient. Values are expressed as picomoles per milligram DNA and the percent of the total is given in parentheses. PC, choline phosphoglycerides; PE, ethanolamine phosphoglycerides; TAG, triacylglycerol; $\mathrm{N}$, normal; Z, Zellweger.

Other types of fibroblasts. 12-HETE oxidation in fibroblasts from patients with a variety of metabolic disorders was examined to determine if the defect in the formation of HETE

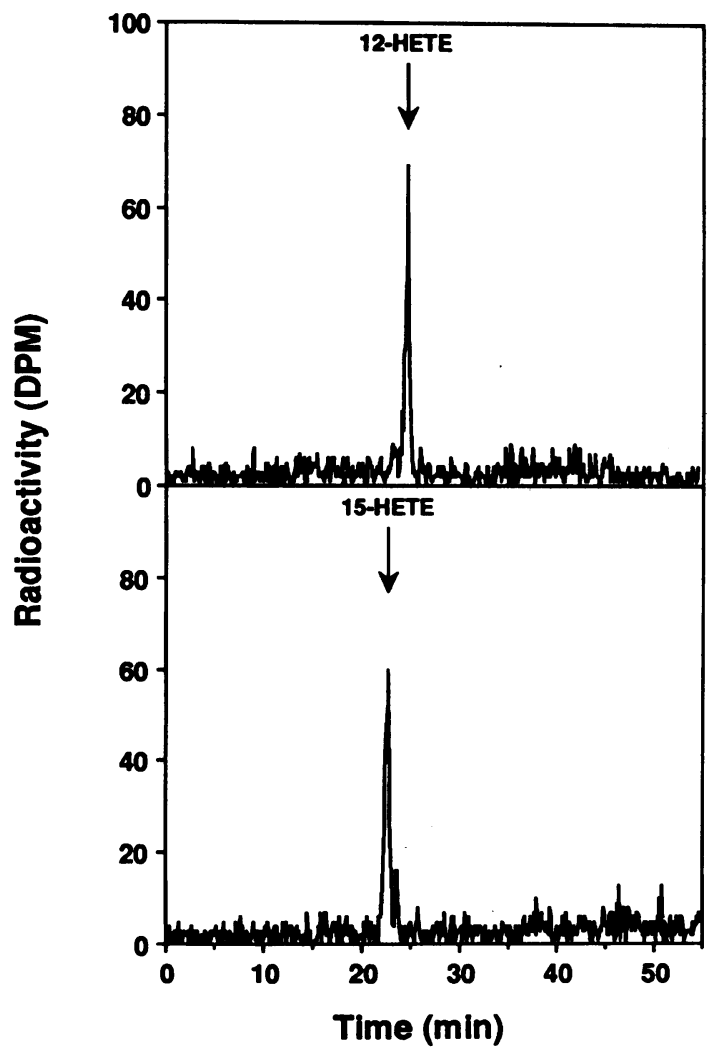

Figure 5. HPLC profile of 12- and 15-HETE radioactivity incorporated into Zellweger fibroblast lipids. Zellweger skin fibroblasts were incubated with $1 \mu \mathrm{M}\left[{ }^{3} \mathrm{H}\right]-12$-HETE (top) or $1 \mu \mathrm{M}\left[{ }^{3} \mathrm{H}\right]-15$-HETE (bottom) in serum-free MEM with $0.1 \mu \mathrm{M}$ BSA for $2 \mathrm{~h}$. Cells were washed with ice-cold buffer, lipids extracted with a chloroform/methanol mixture, and lipid extract saponified with $33 \% \mathrm{KOH}$ in ethanol at $70^{\circ} \mathrm{C}$ for $45 \mathrm{~min}$. After neutralization, saponified lipids were extracted into $n$-heptane or ethyl acetate, transferred to acetonitrile, and an aliquot containing at least $10,000 \mathrm{dpm}$ was injected into the reverse-phase HPLC. Radioactivity was assayed with on-line, flow through scintillation counter. Using this gradient, the retention times of standard 12-HETE (25.4 $\mathrm{min})$ and 15 -HETE $(23.5 \mathrm{~min})$ are indicated by the arrows. metabolites was specific for cells from patients with Zellweger's syndrome (Table III). During a 1-h incubation, similar amounts of $\left[{ }^{3} \mathrm{H}\right]-12-\mathrm{HETE}$ were converted to $16: 3(8-\mathrm{OH})$ by normal adult and normal fetal human fibroblasts, by fibroblasts from patients with cholesteryl ester storage disease, and by fibroblasts from patients with pseudo-Hurler's polylipodystrophy type III. In marked contrast, the Zellweger fibroblasts obtained from three separate patients converted almost no 12-HETE to this metabolite.

Competition with fatty acids. To determine if the oxidation of $\left[{ }^{3} \mathrm{H}\right]-12-\mathrm{HETE}$ oxidation is competitively inhibited by other fatty acids, we measured the production of $16: 3(8-\mathrm{OH})$ in normal human fibroblasts incubated with either an equimolar concentration or a fivefold excess of various unlabeled fatty acids (Table IV). Addition of 5-HETE and 15-HETE reduced the conversion of $\left[{ }^{3} \mathrm{H}\right]-12-\mathrm{HETE}$ to $16: 3(8-\mathrm{OH})$, with 5-HETE being the more effective inhibitor. This inhibitory effect is not

Table III. Production of Major 12-HETE Metabolite in Cultured Human Fibroblasts

\begin{tabular}{lc}
\hline \multicolumn{1}{c}{ Cell type } & Metabolite formed \\
\hline & pmol \\
Normal adult & 933 \\
Normal fetal & 1150 \\
Pseudo-Hurler's polylipodystrophy III & 1019 \\
Cholesteryl ester storage disease & 926 \\
Zellweger's syndrome & \\
Patient 1 & 23 \\
Patient 2 & 18 \\
Patient 3 & 15
\end{tabular}

Each value represents a single measurement from a reverse phaseHPLC determination of the production of the major metabolite from 12-HETE after $1 \mathrm{~h}$ of incubation. Before incubation, the specific activity of $1.0 \mu \mathrm{M}\left[{ }^{3} \mathrm{H}\right]-12-\mathrm{HETE}(0.2 \mu \mathrm{Ci} / \mathrm{ml})$ was determined. After the incubation, radioactivity released into the medium was measured. After ethyl acetate extraction, an aliquot of media containing at least $10,000 \mathrm{dpm}$ was injected into the reverse-phase HPLC. Using the specific activity of the incubation media and the percentage of radioactivity corresponding to the 12-HETE major metabolite obtained from the HPLC analysis, the total amount (picomoles) of 12HETE radioactivity released into the medium was calculated. 
Table IV. Effects of Fatty Acids on the Production of 12-HETE Major Metabolite in Normal Fibroblasts

\begin{tabular}{lcc}
\hline \multicolumn{1}{c}{ Fatty acid } & Concentration & Metabolite formed \\
\hline & $\mu M$ & $p m o l$ \\
Control & & 173 \\
5-HETE & 1 & 44 \\
& 5 & 0 \\
15-HETE & 1 & 109 \\
& 5 & 50 \\
Ricinoleic & 1 & 86 \\
& 5 & 50 \\
Eicosapentaenoic & 5 & 28 \\
Docosahexaenoic & 5 & 17 \\
Phytanic & 5 & 27 \\
Butyric & 1 & 186 \\
& 5 & 139
\end{tabular}

The value for the control is the average of two determinations from two separate cultures. All other values represent a single measurement. A reverse-phase HPLC assay was employed to determine the amount of metabolite produced from 12-HETE after $2 \mathrm{~h}$ of incubation. These values were calculated as described in Table III.

specific for HETEs since another hydroxylated long chain fatty acid, ricinoleic acid, also reduced the formation of 16:3(8$\mathrm{OH})$. In addition, eicosapentenoic and docosahexenoic acid, the major omega- 3 polyunsaturated fatty acids, reduced the conversion of 12-HETE to its major metabolite. Phytanic acid, which undergoes peroxisomal $\beta$-oxidation (29), also markedly reduced 12-HETE oxidation. In contrast, butyrate, which undergoes $\beta$-oxidation in the mitochondria, failed to significantly inhibit the formation of the 12-HETE metabolite when present in equimolar concentrations. At fivefold excess of butyrate, there appeared to be a slight reduction in the conversion of 12-HETE to $16: 3(8-\mathrm{OH})$, but not nearly to the extent that occurred in the presence of any of the other fatty acids tested.

Metabolic function. Four parameters of cell function were measured (Fig. 6) to determine if general metabolic functions in the Zellweger fibroblasts were impaired. Acid lipase activity in the Zellweger fibroblasts was nearly identical to that in the normal fibroblasts (Figure 6, top left), suggesting that lysosomal function is intact. Likewise, Zellweger fibroblasts demonstrated no defect in $\left[1-{ }^{14} \mathrm{C}\right]$ butyrate oxidation (Fig. 6 , top right), indicating that mitochondrial oxidation is not impaired. Likewise, $\left[{ }^{3} \mathrm{H}\right]$ leucine incorporation in both the normal and Zellweger fibroblasts was virtually identical (Fig. 6, bottom left), indicating that total protein synthesis remained intact. In contrast, $\left[{ }^{3} \mathrm{H}\right]$ thymidine incorporation was greater in the normal fibroblasts than in the Zellweger fibroblasts (Fig. 6, bottom right). This is consistent with our empirical observation that the normal fibroblasts grow at a faster rate than the Zellweger fibroblasts.

To determine if 12-HETE accumulation produced any injurious effects in the cells, protein and DNA synthesis also were measured after the cultures were exposed to $2.5 \mu \mathrm{M} 12$ HETE during the 4-h incubations. Addition of 12-HETE produced little change in leucine incorporation in either the normal or Zellweger fibroblasts (Fig. 6, bottom left) and had no effect on thymidine incorporation (Fig. 6, bottom right).
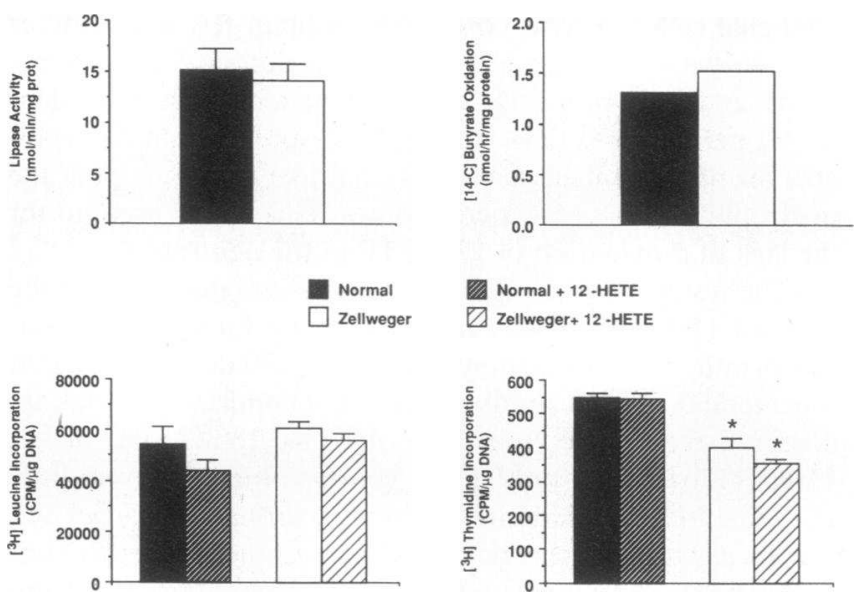

$\square$ Zellweger+ 12 -HETE

Figure 6. Comparison of metabolic functions in normal human and Zellweger skin fibroblasts. Lipase activity (top, left) was measured in confluent cultures as the rate of 4-methylumbelliferone released at $31^{\circ} \mathrm{C}$. Butyrate oxidation (top, right) was measured as the amount of $\left[1-{ }^{14} \mathrm{C}\right]$ butyrate radioactivity incorporated into cellular protein following a 24-h incubation. $\left[{ }^{3} \mathrm{H}\right]$ Leucine incorporation into total cellular protein (bottom, left) and $\left[{ }^{3} \mathrm{H}\right]$ thymidine incorporation (bottom, right) were measured after $4 \mathrm{~h}$ incubations. Separate sets of cultures were incubated in serum-free MEM containing $0.1 \mu \mathrm{M}$ BSA supplemented with $\left[{ }^{3} \mathrm{H}\right]$ leucine or $\left[{ }^{3} \mathrm{H}\right]$ thymidine for $4 \mathrm{~h}$ in the presence of $2.5 \mu \mathrm{M}$ 12-HETE (bottom left and right). Each bar represents the mean and SEM of at least three separate determinations with the exception of the butyrate oxidation, which represent the average of two separate determinations each involving two tissue culture wells. ${ }^{*} P$ $<0.05$ thymidine incorporation, normal vs. Zellweger, compared in the absence and presence of 12-HETE.

\section{Discussion}

The HPLC and TLC data provide evidence that the major 12-HETE metabolite produced by normal fibroblasts is the same as the product formed by MDCK cells, previously identified by gas chromatography-mass spectrometry as 16:3(8$\mathrm{OH})$ (14). This 16-carbon oxidative metabolite also is produced by human vascular smooth muscle cells (15) and murine cerebral microvascular endothelial cells (16). Conversion to $16: 3(8-\mathrm{OH})$ is not the only oxidative pathway for $12-\mathrm{HETE}$. Human neutrophils oxidize 12-HETE to 5,12-diHETE (30) and 12,20-diHETE (31). These diHETEs are formed by lipoxygenase and cytochrome $P_{450}$ pathways, respectively. In the human fibroblast, however, 12-HETE oxidation occurs primarily by the removal of 4 carbons from the carboxyl terminus, presumably through two successive $\beta$-oxidations, as has been observed in the smooth muscle and endothelial cells $(15,16)$. Although the 15-HETE metabolite formed by the normal skin fibroblasts was not identified, its HPLC properties are identical to the product formed from 15-HETE by endothelial cells, 16:3(11-OH) (12). The endothelial cell data also suggest that $16: 3(11-\mathrm{OH})$ is formed as a result of two successive $\beta$-oxidations (12).

A possible explanation for the differences in metabolism of the HETEs in different types of cells may be dependent on peroxisomal number and density. Although peroxisomes are present in all eukaryotic cells except mature erythrocytes, their number and density vary considerably (17). Cells that contain large numbers of peroxisomes include hepatocytes and renal 
epithelial cells, whereas eosinophils contain few peroxisomes (32). In between these extremes are endothelial cells, fibroblasts, and smooth muscle cells, all which contain a low density of peroxisomes (33). Although no specific data are available for neutrophils, it is possible that like the eosinophil, the neutrophil contains few peroxisomes. This would account for the lack of $\beta$-oxidation of 12-HETE in the neutrophil.

The results with the Zellweger fibroblasts indicate that the 12- and 15-HETE oxidation products are formed in peroxisomes rather than mitochondria. Fig. 1 and 3 demonstrate that 4-pentenoic acid, an inhibitor of mitochondrial $\beta$-oxidation, does not reduce the formation of either $16: 3(8-\mathrm{OH})$ or the 15-HETE oxidation product. In contrast, there was very little 12- and 15-HETE oxidation in the peroxisomal-deficient cells. The localization of this defect to peroxisomes is further supported by the comparation between Zellweger fibroblasts and fibroblasts from several other metabolic disorders that do not involve peroxisomes. Fibroblasts obtained from patients with cholesteryl ester storage disease and pseudo-Hurler's polylipodystrophy did not exhibit any reduction in 12-HETE oxidation (Table III). Further support for the peroxisomal location of HETE oxidation is provided by the observation that other highly polyunsaturated and branched-chain fatty acids, known to undergo peroxisomal $\beta$-oxidation (34), diminish conversion of 12-HETE to $16: 3(8-\mathrm{OH})$. Oxidation of monounsaturated long-chain fatty acids and saturated very long-chain fatty acids is thought to occur to a large extent in the peroxisome $(35,36)$. These long- and very long-chain fatty acids are thought to be chain shortened in the peroxisome and, thus, prepared for further catabolism in the mitochondria (34). Conversely, butyrate, a short-chain saturated fatty acid that is oxidized in the mitochondria, did not appreciably reduce 12-HETE oxidation (Table IV). This suggests that the competition occurs mainly at the level of peroxisomal oxidation. Alternatively, the longchain fatty acids may compete with 12-HETE for cellular uptake whereas the short-chain fatty acid butyrate does not.

Why the oxidation of 12- and 15-HETE stops after 4 carbons have been removed and the 16 carbon products are formed is not known. A possible explanation is that the 16:3(8-OH) and $16: 3(11-\mathrm{OH})$ intermediates formed are poor substrates for further peroxisomal oxidation. Another possibility is that the mitochondria, which ordinarily receive the chain shortened peroxisomal products for further $\beta$-oxidation (34), cannot utilize these hydroxylated intermediates. Alternatively, the oxidative process may be designed to stop at the 16 carbon stage because these products of 12- and 15-HETE have some heretofore unrecognized metabolic function, either within the cell in which they are formed or in adjacent cells. Further studies will be needed to resolve this question.

Because of the decreased growth rate and reduced thymidine incorporation, the possibility that the defect in HETE oxidation might be secondary to a generalized metabolic abnormality in the Zellweger fibroblasts was considered. Total protein synthesis as measured by $\left[{ }^{3} \mathrm{H}\right]$ leucine incorporation is not impaired, however, suggesting that anabolic functions are intact in the Zellweger cells. Furthermore, the results with butyrate indicate that mitochondrial oxidation is intact, and the acid lipase data suggest that the production, packaging and secretion of lysosomal enzymes is not impaired. Since the Zellweger fibroblasts take up larger amounts of 12-HETE than the normal fibroblasts, the failure to form the oxidized product is not due to any impairment in uptake. Likewise, there ap- pears to be no impairment in the ability of the Zellweger cells to incorporate 12-HETE into phospholipids and triacylglycerol. Although the Zellweger cells retain more 12-HETE in these lipids (Table II), they do not trap measurable amounts of the oxidized product and thereby prevent it from being secreted (Fig. 5). Thus, the lack of HETE metabolism in the Zellweger fibroblasts probably is not due to a general impairment of overall cell function but rather, appears due to the specific absence of normally functioning peroxisomes.

At all time points examined, 12-HETE uptake and incorporation was greater in the Zellweger than in the normal fibroblasts (Fig. 4). The majority of the 12-HETE radioactivity was incorporated into the phospholipid fraction, primarily the choline and ethanolamine phosphoglycerides (Table II), similar to what has been described in other cultured cells (1). These findings indicate that 12-HETE accumulates intracellularly when there is peroxisomal deficiency, probably because it cannot be adequately oxidized. Since the phospholipids are contained almost entirely in bilayer structures in mammalian cells, much of the 12-HETE accumulation probably occurs in membrane structures. Because of this, the possibility that some cytotoxicity may result from the 12-HETE accumulation in peroxisomal deficient cells was examined. However, the protein and DNA synthesis data argue against this (Fig. 6). Addition of $2.5 \mu \mathrm{M}$ 12-HETE to the incubation medium had no significant effect on leucine or thymidine incorporation in either the normal or Zellweger fibroblasts during a 4-h incubation. Thus, general metabolic function appears to remain intact even when peroxisomal deficient cells accumulate substantial amounts of 12-HETE.

In summary, Zellweger fibroblasts are unable to metabolize the lipoxygenase products 12- and 15-HETE. This defciency appears to be a specific result of peroxisomal deficiency since fibroblasts with other metabolic abnormalities do not demonstrate this defect. Lack of peroxisomal $\beta$-oxidation of hydroxyeicosanoids represents a new and previously unrecognized metabolic defect that occurs in a peroxisomal deficiency syndrome. Whether the lack of HETE oxidation contributes to the phenotypic expression seen in infants with Zellweger's syndrome remains to be determined.

\section{Acknowledgments}

The secretarial assistance of Cay Wieland and technical assistance of Michelle Rocca are gratefully acknowledged. The authors wish to thank Dr. Shivanand Patil, Director of the Cytogenetics Laboratory in the Department of Pediatrics, University of Iowa College of Medicine, for providing the skin fibroblasts from the patients with Zellweger's Syndrome and Dr. Gloria Sando, Department of Internal Medicine, University of Iowa College of Medicine for supplying the skin fibroblasts from normal patients.

Dr. Gordon is a recipient of a Clinician-Scientist Award of the American Heart Association (87-0426) and a Young Investigator Award of the National Kidney Foundation. This work was also supported by an Arteriosclerosis Specialized Center of Research grant HL-14230 from the National Heart, Lung and Blood Institute, National Institutes of Health.

\section{References}

1. Spector, A. A., J. A. Gordon, and S. A. Moore. 1988. Hydroxyeicosatetraenoic Acids (HETEs). Prog. Lipids Res. 27:271-323.

2. Hamberg, M., and B. Samuelsson. 1974. Novel transformation 
of arachidonic acid in human platelets. Proc. Natl. Acad. Sci. USA. 71:3400-3404.

3. Rabinovitch, H. J., J. Durand, M. Rigand, F. Mendy, and J. C. Bretow. 1981. Transformation of arachidonic acid into monohydroxy-eicosatetraenoic acids by mouse peritoneal macrophages. Lipids. 16:518-524.

4. Goetzl, E., J. M. Woods, and R. R. Gorman. 1977. Stimulation of human eosinophil and neutrophil polymorphonuclear leukocyte chemotaxis and random migration by $12-\mathrm{L}-5,8,10,14$-eicosatetraenoic acid. J. Clin. Invest. 59:179-183.

5. Yamaja Setty, B., J. E. Graeber, and M. J. Stuart. 1987. The mitogenic effect of 15- and 12-hydroxyeicosatetraenoic acid on endothelial cells may be mediated via diacylglycerol kinase. J. Biol. Chem. 262:17613-17622.

6. Hadjiagapiou, C., and A. A. Spector. 1986. 12-Hydroxyeicosatetraenoic acid reduces prostacyclin production by endothelial cells. Prostaglandins. 31:1135-1144.

7. Gordon, J. A. and A. A. Spector. 1987. Effects of 12-HETE on renal tubular epithelial cells. Am. J. Physiol. 253:C277-C285.

8. Vanderhoek, J. Y., R. W. Bryant, and J. M. Bailey. 1980. Inhibition of leukotriene biosynthesis by the leukocyte product 15-hydroxy5,8,11,13-eicosatetraenoic acid. J. Biol. Chem. 255:10064-10066.

9. Vanderhoek, J. Y., M. T. Karmin, and S. L. Ekkborg. 1985. Endogenous hydroxyeicosatetraenoic acids stimulate the human polymorphonuclear leukocyte 15-lipoxygenase pathway. J. Biol. Chem. 260:15482-15487.

10. Yamaja Setty, B. N., and M. J. Stuart. 1986. 15-Hydroxy5,8,11,13-eicosatetraenoic acid inhibits human vascular cyclooxygenase: potential role in diabetic vascular disease. J. Clin. Invest. 77:202211.

11. Johnson, H. G., M. L. McNee, and F. F. Sun. 1985. 15-hydroxyeicosatetraenoic acid is a potent mediator and agonist of canine tracheal mucus secretion. Am. Rev. Respir. Dis. 131:917-922.

12. Shen, X. Y., P. H. Figard, T. L. Kaduce, and A. A. Spector. 1988. Conversion of 15-hydroxyeicosatetraenoic acid to 11-hydroxyhexadecatrienoic acid by endothelial cells. Biochemistry. 27:996-1004.

13. Pawlowski, H. A., W. A. Scott, M. Andreach, and Z. A. Cohn. 1982. Uptake and metabolism of monohyderoxyeicosatetraenoic acids by macrophages. J. Exp. Med. 155:1653-1664.

14. Gordon, J. A., P. H. Figard, and A. A. Spector. 1989. Identification of the major metabolite of 12-HETE produced by renal tubular epithelial cells. J. Lipid Res. 30:731-738.

15. Hadjiagapiou, C., H. Sprecher, T. L. Kaduce, P. H. Figard, and A. A. Spector. 1987. Formation of 8-hydroxyhexadecatrienoic acid by vascular smooth muscle cells. Prostaglandins. 34:579-589.

16. Moore, S. A., L. J. Prokuski, P. H. Figard, A. A. Spector, and M. N. Hart. 1988. Murine cerebral microvascular endothelium incorporate and metabolize 12-hydroxyeicosatetraenoic acid. J. Cell Physiol. 137:75-85.

17. Lazarow, P. B. and H. W. Moser. 1989. Disorders of Peroxisome Biogenesis. In The Metabolic Basis of Inherited Disease. C. R. Scriver, A. B. Beaudet, W. S. Sly, and D. Valle, editors. McGraw-Hill Inc., Philadelphia, PA. 1479-1510.

18. Goldfischer, S., C. L. Moore, A. B. Johnson, A. J. Spiro, M. P. Yalsamis, H. K. Wisniewski, R. H. Ritch, W. T. Norton, I. Rapin, and L. M. Gartner. 1973. Peroxisomal and mitochondrial defects in the cerebrophepatorenal syndrome. Science (Wash. DC). 182:62-64.

19. Hiltunen, J. K., T. Karki, I. E. Hassinene, and H. Osmundsen. 1986. $\beta$-Oxidation of polyunsaturated fatty acids by rat liver peroxisomes. J. Biol. Chem. 16484-16493.
20. Scherpers, L., M. Casteels, J. Yamecq, G. Parmentier, P. P. Van Veldhoven, and G. P. Mannaerts. 1988. $\beta$-Oxidation of the carboxyl side chain of prostaglandin $E_{2}$ in the rat liver peroxisomes and mitochondria. J. Biol. Chem. 263:2724-2731.

21. Diczafalusy, U., E. H. Alexson, and J. I. Pedersen. 1987. Chain shortening of prostaglandin $F_{2 \alpha}$ by rat liver peroxisomes. Biochem. Biophys. Res. Commun. 144:1206-1213.

22. Labarca, C., and K. Paisen. 1980. A simple, rapid and sensitive DNA assay procedure. Anal. Biochem. 102:344-352.

23. Fales, H. M., T. M. Jaouni, and J. F. Babaashak. 1973. Simple device for preparing ethereal diazomethane without resorting to codistillation. Anal. Chem. 45:2302-2303.

24. Maas, R., L. L. J. Turck, J. A. Oates, and A. R. Brash. 1982. Formation of a novel acid from arachidonic acid by lipoxygenase-catalyzed double oxygenation in rat mononuclear cells and human leukocytes. J. Biol. Chem. 257:7065-7062.

25. Rhead, W. J., A. Moon, V. Roettger, and K. Henkle. 1985. ${ }^{14} \mathrm{C}$-labeled substrate catabolism by human diploid fibroblasts derived from infants and adults. Biochem. Med. 34:182-188.

26. Lees, M. B., and S. Paxman. 1972. Modification of the Lowry procedure for the analysis of proteolipid protein. Anal. Biochem. 47:184-192.

27. Sando, G. N., and L. M. Rosenbaum. 1985. Human lysosomal acid lipase/cholesteryl ester hydrolase: purification and properties of the form secreted by fibroblasts in microcarrier culture. J. Biol. Chem. 260:15186-15193.

28. Winer, B. J. 1971. Statistical principles in experimental design, McGraw-Hill Book Co., New York. 907.

29. Poulos, S., F. Sharp, and M. Whiting. 1984. Infantile Refsum's disease (phytanic acid storage disease). A variant of Zellweger syndrome? Clin. Gen. 26:579-586.

30. Marcus, A. J., M. J. Broekman, L. B. Safier, H. L. Ullman, N. Islam, C. N. Serhan, L. E. Rutherford, H. M. Korchak, and G. Weissman. 1982. Formation of leukotrienes and other hydroxy acids during platelet-neutrophil interactions in vivo. Biochem. Biophys. Res. Commun. 109:130-137.

31. Marcus, A. J., L. B. Safier, H. L. Ullman, M. J. Broekman, N. Islam, T. D. Oglesby, and R. R. Gorman. 1984. 12S-20-dihydroxyeicosatetraenoic acid: a new eicosanoid synthesized by neutrophils from 12-S-hydroxyeicosatetraenoic acid produced by thrombin in collagen stimulated platelets. Proc. Natl. Acad. Sci. USA. 81:903-907.

32. Novikoff, A. B., P. M. Novikoff, C. Davis, and N. Quintana. 1973. Studies on microperoxisomes. V. Are microperoxisomes ubiquitious in mammalian cells? J. Histochem. Cytochem. 21:737-755.

33. Hruban, Z., E. L. Vigil, A. Slesers, and E. Hopkins. 1972. Microbodies: constituent organelles of animal cells. Lab. Invest. 27:184-191.

34. Wanders, R. J. A., C. W. T. van Roemund, MI J. A. van Wijland, R. B. H. Schutgens, J. H. Heikoop, H. van den Bosch, A. W. Schram, and J. M. Tager. 1987. Peroxisomal fatty acid $\beta$-oxidation in relation to the accumulation of very long chain fatty acids in cultured skin fibroblasts from patients with Zellweger syndrome and other peroxisomal disorders. J. Clin. Invest. 80:1778-1783.

35. Bremer, J., and K. R. Norum. 1982. Metabolism of very long chain monounsaturated fatty acids (C22:1) and their adaptation to their presence in the diet. J. Lipid Res. 23:243-256.

36. Singh, I., A. B. Moser, S. Goldfischer, and H. W. Moser. 1984. Lignoceric acid is oxidized in the peroxisome: implications for the Zellweger crebro-hepato-renal syndrome and adrenoleukodystrophy. Proc. Natl. Acad. Sci. USA. 81:4203-4207. 